Andrews University

Digital Commons @ Andrews University

Faculty Publications

$1-1-2010$

\title{
Socially Induced Synchronization of Every-other-day Egg Laying in a Seabird Colony
}

Shandelle M. Henson

Andrews University, henson@andrews.edu

James L. Hayward

Andrews University, hayward@andrews.edu

J. M. Cushing

The University of Arizona

Joseph C. Galusha

Walla Walla University

Follow this and additional works at: https://digitalcommons.andrews.edu/pubs

Part of the Ornithology Commons

\section{Recommended Citation}

Henson, Shandelle M.; Hayward, James L.; Cushing, J. M.; and Galusha, Joseph C., "Socially Induced Synchronization of Every-other-day Egg Laying in a Seabird Colony" (2010). Faculty Publications. 1764. https://digitalcommons.andrews.edu/pubs/1764

This Article is brought to you for free and open access by Digital Commons @ Andrews University. It has been accepted for inclusion in Faculty Publications by an authorized administrator of Digital Commons @ Andrews University. For more information, please contact repository@andrews.edu. 


\title{
SOCIALLY INDUCED SYNCHRONIZATION OF EVERY-OTHER-DAY EGG LAYING IN A SEABIRD COLONY
}

\author{
Shandelle M. Henson, ${ }^{1,5}$ James L. Hayward, $^{2}$ J. M. Cushing, ${ }^{3}$ and Joseph G. Galusha ${ }^{4}$ \\ ${ }^{1}$ Department of Mathematics, Andrews University, Berrien Springs, Michigan 49104, USA; \\ ${ }^{2}$ Department of Biology, Andrews University, Berrien Springs, Michigan 49104, USA; \\ ${ }^{3}$ Department of Mathematics and Program in Applied Mathematics, University of Arizona, Tucson, Arizona 85721, USA; and \\ ${ }^{4}$ Department of Biological Sciences, Walla Walla University, College Place, Washington 99324, USA
}

\begin{abstract}
AвSTRACT.-Spontaneous oscillator synchrony has been documented in a wide variety of electrical, mechanical, chemical, and biological systems, including the menstrual cycles of women and estrous cycles of Norway Rats (Rattus norvegicus). In temperate regions, many colonial birds breed seasonally in a time window set by photoperiod; some studies have suggested that heightened social stimulation in denser colonies can lead to a tightened annual reproductive pulse. It has been unknown, however, whether the analog of menstrual synchrony occurs in birds - that is, whether avian ovulation cycles can synchronize on a daily timescale within the annual breeding pulse. We report every-other-day clutch-initiation and egg-laying synchrony in a breeding colony of Glaucous-winged Gulls (Larus glaucescens) and show that the level of synchrony declined with decreasing colony density. We also pose a mathematical model based on the hypothesis that preovulatory luteinizing hormone surges synchronize through social stimulation. Model predictions are consistent with observations. Finally, we suggest a procedure for identifying synchronous egg laying in other colonies and species. Received 14 October 2009, accepted 7 March 2010.
\end{abstract}

Key words: egg laying, Glaucous-winged Gull, Larus glaucescens, luteinizing hormone, mathematical model, ovulation, synchrony.

\section{Sincronización de la Puesta de Huevos en Días Alternos Inducida Socialmente en una Colonia de Aves Marinas}

RESUMEN.-La sincronía oscilatoria espontánea se ha documentado en una gran variedad de sistemas eléctricos, mecánicos, químicos y biológicos, incluyendo la sincronización de los ciclos menstruales de las mujeres y los ciclos estrales de Rattus norvegicus. En las regiones templadas, muchas aves coloniales se reproducen estacionalmente en un momento determinado por el fotoperíodo; algunos estudios han sugerido que la intensificación del estímulo social en colonias con altas densidades poblacionales puede llevar a un pulso reproductivo anual compactado. Sin embargo, se desconoce si el caso análogo a la sincronización menstrual ocurre en aves, esto es, si es que los ciclos ovulatorios de las aves pueden sincronizarse a una escala diaria dentro del pulso reproductivo anual. Aquí, documentamos la sincronía en la iniciación de la puesta y puesta de huevos en días alternos en una colonia reproductiva de la gaviota Larus glaucescens y mostramos que el nivel de sincronía disminuyó con la disminución de la densidad en la colonia. También presentamos un modelo matemático basado en la hipótesis de que los pulsos de la hormona luteinizante preovulatoria se sincronizan a través de estímulos sociales. Las predicciones del modelo son consistentes con las observaciones. Por último, sugerimos un procedimiento para identificar la sincronía de la puesta de huevos en otras colonias y en otras especies.

SYNCHRONIZATION OF OSCILLATORS can result from environmental forcing or can occur as a phenomenon of spontaneous self-organization. In the former case, an external periodic cue mediates the synchrony, much as a periodic traffic light regulates the pulse of automobiles on city streets. In the latter case, interacting oscillators spontaneously adjust phase or period and begin cycling together, much as runners on a track adjust speeds in order to run alongside friends. Oscillators known to synchronize spontaneously include cardiac pacemaker cells, Malaysian fireflies, pendulum clocks, laser photon emitters, and chemical reactions
(Pikovsky et al. 2003, Strogatz 2003). In rats, estrous cycles synchronize through social stimulation (McClintock 1984a, b); similarly, synchronized menstruation can occur in women who live together (McClintock 1971), with pheromones acting as synchronizing olfactory signals (McClintock 1998).

In temperate regions, many colonial birds breed approximately synchronously on a yearly timescale within a time window set by photoperiod (Nicholls et al. 1988); this type of synchrony is environmentally forced. Some studies have suggested that heightened social stimulation in denser colonies can lead to a tightened annual

${ }^{5}$ E-mail: henson@andrews.edu

The Auk, Vol. 127, Number 3, pages 571-580. ISSN 0004-8038, electronic ISSN 1938-4254. @ 2010 by The American Ornithologists' Union. All rights reserved. Please direct all requests for permission to photocopy or reproduce article content through the University of California Press's Rights and Permissions website, http://www.ucpressjournals. com/reprintInfo.asp. DOI: 10.1525/auk.2010.09202 
reproductive pulse, a type of spontaneous synchronization known as the "Fraser Darling effect" (Darling 1938). It has been unknown, however, whether avian ovulation cycles can synchronize on a daily timescale within the annual breeding pulse, the occurrence of which would be analogous to menstrual synchrony in women.

Birds, like mammals, experience hormone oscillations that drive the ovulation cycle. In mammals, the cycle is interrupted by fertilization, and after gestation the entire brood is birthed in a single episode. By contrast, many birds ovulate and oviposit (lay eggs) at species-specific intervals over several days until clutch completion (Wiebe and Martin 1995). Periodic surges of luteinizing hormone (LH) are associated with oviposition and ovulation in birds. For example, domestic turkeys and chickens experience LH surges at approximately 24-h intervals; oviposition occurs a few hours after an LH surge, followed $\sim 30$ min later by ovulation of the next mature follicle (Liu et al. 2001). Spontaneous ovulation synchrony in these birds might be difficult to differentiate from circadian entrainment (Yang et al. 2000). Glaucous-winged Gulls (Larus glaucescens), however, lay eggs at approximately 2-day intervals (Vermeer 1963). Ovulation synchrony in these birds likely would be associated with every-other-day synchronous egg laying, a novel outcome unlikely to be conflated with environmental forcing.

Over the course of a study of reproductive success of colonially breeding Glaucous-winged Gulls in the state of Washington, we noticed what appeared to be an every-other-day pulse in the number of new eggs laid. We tested the observed patterns in egg laying to see whether they differed significantly from the patterns that would be expected to occur by chance. Here, we report the results of our analysis, with three aims: (1) to demonstrate the occurrence of egg-laying synchrony by rigorously testing three null hypotheses with Monte Carlo methods; (2) to construct a mathematical model based on a hypothetical mechanism for synchrony and compare model predictions to data; and (3) to suggest a procedure for identifying synchronous egg laying in other colonies and species.

\section{Methods}

Colony description.-We monitored egg laying from 2006 to 2008 in a breeding colony at Protection Island National Wildlife Refuge $\left(48^{\circ} 08^{\prime} \mathrm{N}, 122^{\circ} 55^{\prime} \mathrm{W}\right)$, Washington. The colony contains $>2,400$ nests and is located on a gravel spit (Violet Point) that extends to the island's southeast (Fig. 1). The colony, which extends throughout the spit, is spatially heterogeneous, consisting of densely populated, socially coherent neighborhoods ("clubs") separated by areas with few or no territories. Egg-laying data were collected from five rectangular sample areas near the west end of the colony (areas A-E; Fig. 1). Each sample area was centered on and contained one club. Areas $C$ and $D$ shared a geographic boundary, but their clubs were separated by a thinly populated region. Areas A, $B$, and $E$ were separated geographically from each other and from areas $\mathrm{C}$ and $\mathrm{D}$. We did not study other clubs that were situated to the south and to the east of areas A-E.

We monitored the sample areas daily, in the afternoon, on foot, throughout the laying season (late May-June). New nests were staked and numbered upon clutch initiation, and each staked nest was checked for new eggs, which were then marked and recorded. For each sample area, we measured the nest density by computing the mean "nearest neighbor" (NN) distance, which

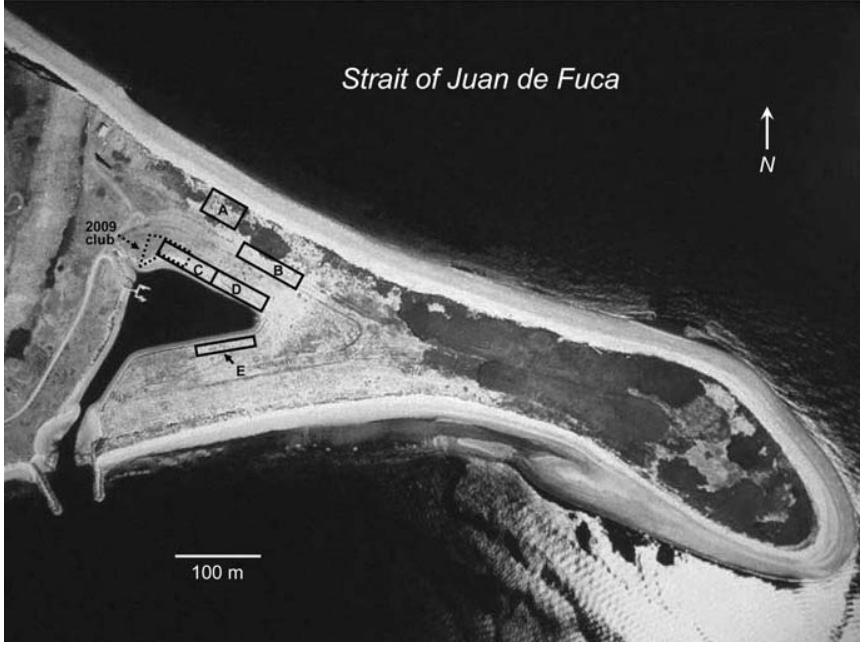

FIG. 1. Glaucous-winged Gull sample areas A-E on Violet Point, Protection Island National Wildlife Refuge, Washington (2006-2008; solid lines), and the "club" (see text) studied in 2009 (dotted line).

was defined as the distance from the center of a focal nest to the center of the nearest neighboring nest (Patterson 1965).

In 2006, 2007, and 2008, the total numbers of monitored nests across all five sample areas were 228, 229, and 233, respectively; mean $( \pm$ SD) clutch sizes were $2.46 \pm 0.75,2.41 \pm 0.83$, and $2.50 \pm$ 0.67 , respectively, with intraclutch mean laying intervals of $2.18 \pm$ $0.96,2.46 \pm 0.82$, and $2.28 \pm 0.73$, respectively. Over the five sample areas and 3 years, mean nearest-neighbor distances ranged from $1.94 \pm 0.73 \mathrm{~m}$ to $3.54 \pm 1.84 \mathrm{~m}$. These values are consistent with other reports for this species (Vermeer 1963, Zador and Piatt 2007).

The year 2008 was a La Niña year in which the local average March-June air temperature was $2.3^{\circ} \mathrm{C}$ and $0.9^{\circ} \mathrm{C}$ cooler than in 2006 and 2007, respectively (National Oceanographic and Atmospheric Administration's [NOAA] National Data Buoy Center, Station 46088, New Dungeness), and local average sea-surface temperature was $0.7^{\circ} \mathrm{C}$ degrees cooler than in both 2006 and 2007 (NOAA National Data Buoy Center, Station PTWW1-9444900, Port Townsend). The mean clutch-initiation date for all five areas was 4.4 days later than in 2006, and 6.4 days later than in 2007. This is consistent with other work that has shown that clutch initiation is delayed during cool weather in this and similar species (Verbeek 1979, Schreiber 2001).

Measure of synchrony.-Glaucous-winged Gulls lay eggs at approximately 2-day intervals and typically lay 2 or 3 eggs (Vermeer 1963). In a perfectly synchronized social group of these birds, the number of clutches initiated per day (and the total number of ovipositions per day) would exhibit an oscillation of period 2 with every-other-day "highs" of irregular height and "lows" equal to zero (Fig. 2A). Because the average egg-laying interval is slightly greater than 2 days (Vermeer 1963), and because there can be temporal gaps during which no clutches are initiated, such a perfectly synchronous time series could experience occasional "skips" of two or more zeros in a row (Fig. 2A). Although perfect synchrony of this type would be easy to identify in data, the ubiquitous presence of stochasticity in ecological systems requires quantifying the degree of synchrony in noisy time series (Fig. 2B-E). 


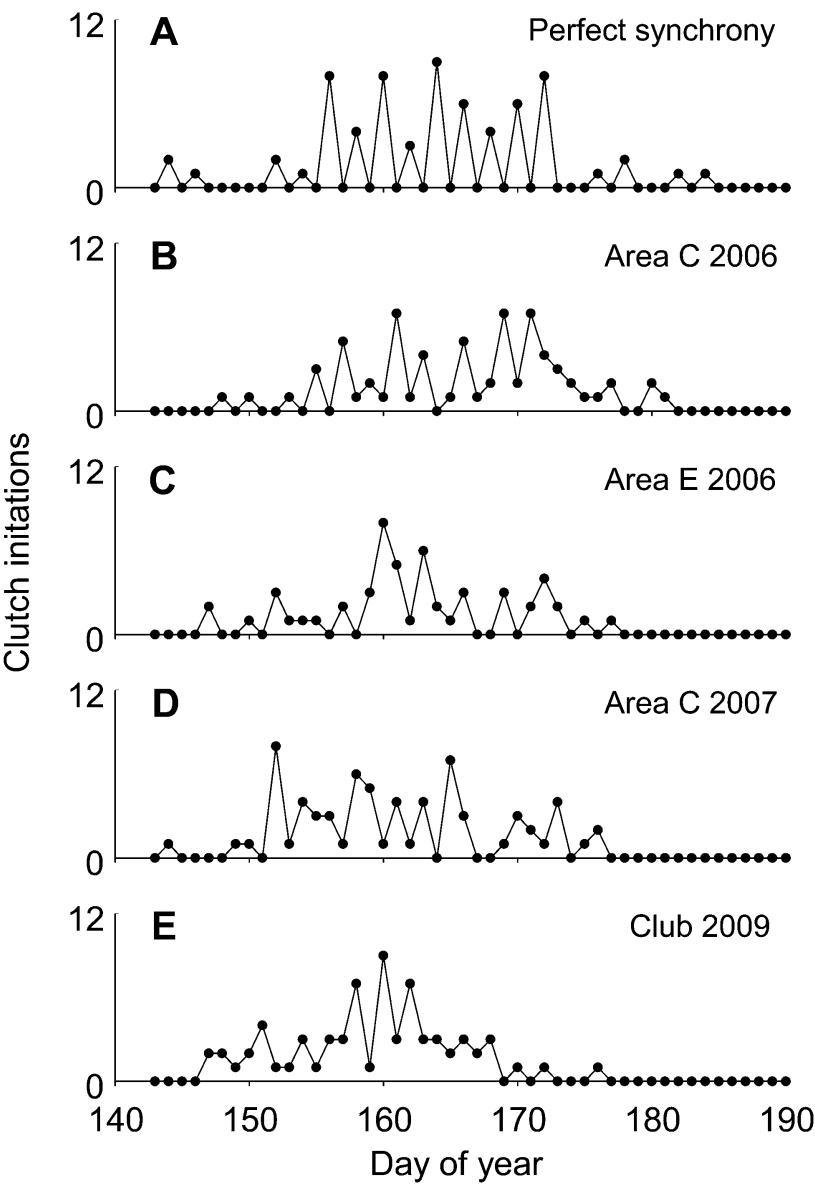

FIG. 2. Number of clutch initiations per day among Glaucous-winged Gulls at Violet Point, Protection Island National Wildlife Refuge, Washington. (A) Perfect synchrony in simulated time series. (B) Observed data, area C 2006. Significant level of process synchrony $\left(P=0.0006\right.$ for $\left.\mathrm{H}_{\mathrm{N}}\right)$. (C) Observed data, area E 2006. Significant level of process synchrony $\left(P=0.004\right.$ for $\left.H_{N}\right)$. (D) Observed data, area C 2007. Significant level of process synchrony $\left(P=0.001\right.$ for $\left.\mathrm{H}_{\mathrm{N}}\right)$. (E) Observed data, "club" from 2009. Some evidence of process synchrony $\left(P=0.077\right.$ for $\left.\mathrm{H}_{\mathrm{N}}\right)$.

We defined a measure $z$ of synchrony for time series of the form $E_{1}, E_{2}, E_{3}, \ldots, E_{m}$ in which $E_{i}$ is the number of eggs laid on day $i$, and days 1 and $m$ refer to the first and last days on which eggs were laid:

$$
z=\frac{\sum_{i=0}^{m}\left|E_{i+1}-E_{i}\right|}{2 \sum_{i=1}^{m} E_{i}}
$$

where $E_{0}$ and $E_{m+1}$ are defined as zero. The numerator measures the actual "up-and-down" variation of the time-series graph; the denominator gives the up-and-down variation for any perfectly synchronous time series with the same total

$$
N=\sum_{i=1}^{m} E_{i}
$$

The value $z=1$ indicates perfect synchrony, and $z<1$ indicates a departure from perfect synchrony. For example, the perfectly synchronous time series $5,0,10,0,0,8(N=23)$ yields $z=1$, and the time series $4,1,8,2,8(N=23)$ yields $z \cong 0.74$.

We computed $z$ values separately for clutch-initiation and total-oviposition time-series data.

\section{MODELS}

Null models.-To test whether the observed time series showed a level of synchrony that differed significantly from that expected to occur by chance, we tested the predictions of three null Monte Carlo models. We describe each null model first by stating the hypothesis on which it was based and then give a complete description of the procedure used to create simulated time series.

$H_{N}$ : Clutch initiations were random-normally distributed in time.-For each observed time series of clutch initiations, we computed the total number of clutches initiated $(N)$, the number of days spanning the clutch-initiation period $(m)$, and the sample mean clutch-initiation date and standard deviation $(\bar{d}$ and $s)$. In each Monte Carlo simulation based on hypothesis $\mathrm{H}_{\mathrm{N}}$, we randomly selected $N$ real numbers from a truncated normal distribution Norm $\left(\bar{d}, s^{2}\right)$ lying within the time interval $[0, m]$, and then we binned the $N$ numbers by 1-day intervals to produce a simulated clutch-initiation time series.

$H_{U}:$ Clutch initiations were random-uniformly distributed in time.-The simulations of $\mathrm{H}_{\mathrm{U}}$ were computed in the same way as for $\mathrm{H}_{\mathrm{N}}$ except that the truncated normal distribution was replaced by a uniform distribution on the time interval $[0, m]$.

$H_{A}$ : All ovipositions were random-normally distributed in time.-In each Monte Carlo simulation, we random-normally distributed the observed clutches by random-normally distributing clutch-initiation dates, as for $\mathrm{H}_{\mathrm{N}}$. Within each clutch, we randomly selected laying intervals from a normal distribution with mean and variance equal to those of the observed intervals. Finally, we binned all simulated ovipositions into 1-day intervals to produce a simulated oviposition time series.

For each null model, we used the program MATLAB (MathWorks, Natick, Massachusetts) to compare $z_{\text {obs }}$ for the observed time series with the distribution of $z$ values estimated from $10^{6}$ simulated time series. $P$ values were computed as the proportion of simulations satisfying $z \geq z_{\mathrm{obs}}$. Each of the resulting $P$ values was computed five times to check convergence of the result. We also computed the critical value $z_{\text {crit }}$ corresponding to significance level $\alpha=0.01$.

The distributions of $z$ values generated by the null models depend on model parameters (e.g., $N, m, \bar{d}$, and $s$ in model $\mathrm{H}_{\mathrm{N}}$ ). Because the observed parameters were different for each of the 15 data sets (5 sample areas over 3 years), we computed the predicted distribution separately for each data set. This made it more difficult to reject the null models and, hence, made the test of the null models more rigorous.

For a particular time series, rejection of the null models indicates a level of synchrony unlikely to be attained by chance. We say that such a time series exhibits "process synchrony."

Process model.-For most avian species that breed in temperate regions, the starting and ending times of the reproductive window are set by photoperiod. As the light:dark ratio increases in the spring, photic stimulation of the avian hypothalamus results 
in dramatic growth of the gonads. In many species, prolonged exposure to long days eventually results in loss of reproductive responsiveness to photic stimulation, a phenomenon known as "photorefractoriness." The timings of the associated peak and decline of baseline LH levels are set by photoperiod and probably are independent of temperature. However, the actual onset of ovulation cycling within the reproductive window, heralded in each female by an initial LH surge, can depend on "final cues," including temperature (Faaborg 1988; Nicholls et al. 1988; Hahn et al. 1997, 2009; Wingfield et al. 2003; Dawson and Sharp 2007; Hahn and MacDougall-Shackleton 2008; Wingfield 2008). Cool weather, for example, can delay the onset of ovulation in gulls (Verbeek 1979, Schreiber 2001).

A hypothesized 2-day ovulation cycle can be divided into two parts. The first day contains the LH surge and ovulation. During the second day, the ovum (the yolk of which was laid down in the ovary before ovulation) moves through the oviduct and the albumen and shell membrane are laid down (Faaborg 1988). The shell is formed and the egg is laid on the third day (the first day of the next cycle), after the next LH surge. Oviposition is followed rapidly by ovulation of the next follicle in the hierarchy.

To probe the possible mechanisms behind every-other-day egg-laying synchrony, we constructed a mathematical model based on the following assumptions. $\left(\mathrm{M}_{1}\right)$ Baseline LH levels peak at a time set by photoperiod, independent of temperature, and then decline. $\left(\mathrm{M}_{2}\right)$ The probability that an individual will experience the initial LH surge is proportional to its baseline LH level and the average ambient temperature. In particular, cool weather can delay the initial LH surge. $\left(\mathrm{M}_{3}\right)$ Ovulating Glaucous-winged Gulls experience every-other-day LH surges. LH surges in neighbors synchronize through social stimulation, the strength of which is proportional to the baseline LH level and inversely proportional to the NN distance.

We first construct simple phenomenological expressions as proxies for baseline LH level and temperature. We describe the dynamics of the baseline LH level (qualitatively, not quantitatively) with a quadratic curve starting from a peak value of 1 and declining to zero:

$$
R_{t}=\max \left[1-\left(\frac{t}{r}\right)^{2}, 0\right]
$$

where $r>0$ is the number of days from peak LH level to complete refraction and $\max [\cdot, 0]$ constrains the value of $R_{t}$ to be non-negative (Fig. 3A; assumption $\mathrm{M}_{1}$ ). We depict the qualitative behavior of springtime average ambient temperature by the increasing function

$$
T_{t}=b(\max [(t-a), 0])^{2}
$$

where $a \geq 0$ is the number of days that warm weather is delayed and $b>0$ (Fig. 3A)

We take the probability $f$ that a female is ready to experience the initial LH surge to be proportional to both temperature and baseline LH level:

$$
f_{t}=\min \left[R_{t} T_{t}, 1\right]
$$
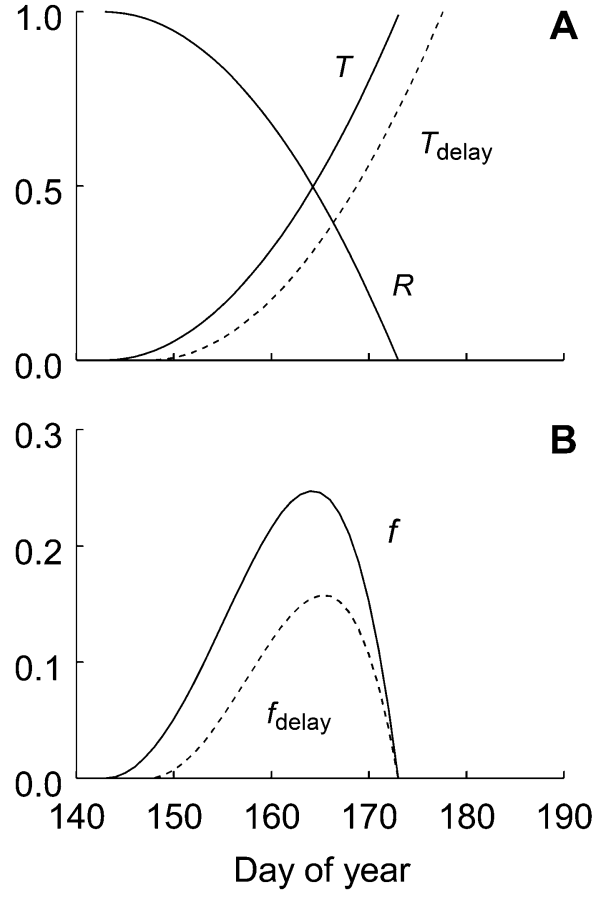

FiG. 3. Submodels for baseline luteinizing hormone (LH) and temperature. (A) Baseline $\mathrm{LH}$ function $R$, temperature function $T$, and temperature function with delay $T_{\text {delay' }}$ as in Models 2 and 3. (B) Probability of initial LH surge, with and without temperature delay ( $f_{\text {delay }}$ and $f$, respectively), as in Model 4.

where $\min [\cdot, 1]$ constrains the value of $f$ to be $\leq 1$ (Fig. 3B; assumption $\mathrm{M}_{2}$ ). Finally, we model the strength of social stimulation $c$ as proportional to baseline LH and inversely proportional to mean NN distance:

$$
c_{t}=\frac{\tilde{c} R_{t}}{N N}
$$

where $\widetilde{c}>0$ is the constant of proportionality (assumption $\mathrm{M}_{3}$ ).

The discrete-time process-synchrony model, based on the compartmental diagram in Figure 4, is

$$
\begin{aligned}
& w_{t+1}=\left(1-f_{t}\right) w_{t}+f_{t}\left(1-e^{-c_{t} x_{t}}\right) w_{t} \\
& x_{t+1}=f_{t} w_{t} e^{-c_{t} x_{t}}+q y_{t} e^{-c_{t} x_{t}} \\
& y_{t+1}=x_{t}+q\left(1-e^{-c_{t} x_{t}}\right) y_{t}
\end{aligned}
$$

where the discrete time step is 1 day and $t=0$ corresponds to the day of peak baseline LH levels. Here, $w_{t}$ is the number of birds on day $t$ that have not begun to cycle, $x_{t}$ is the number of birds in the first phase of the ovulation cycle on day $t$, and $y_{t}$ is the number of birds in the second phase of the ovulation cycle on day $t$. The fraction $f_{t}$ is the probability that a noncycling individual is ready to experience the initial $\mathrm{LH}$ surge and begin cycling, and $\left(1-e^{-c_{t} x_{t}}\right)$ is the probability that a cycling individual or one ready to cycle will "skip" a day in order to synchronize, where $c_{t}$ is the strength of social stimulation. The fraction $1-q$ is the probability that a bird in the second phase of the cycle will stop cycling and 


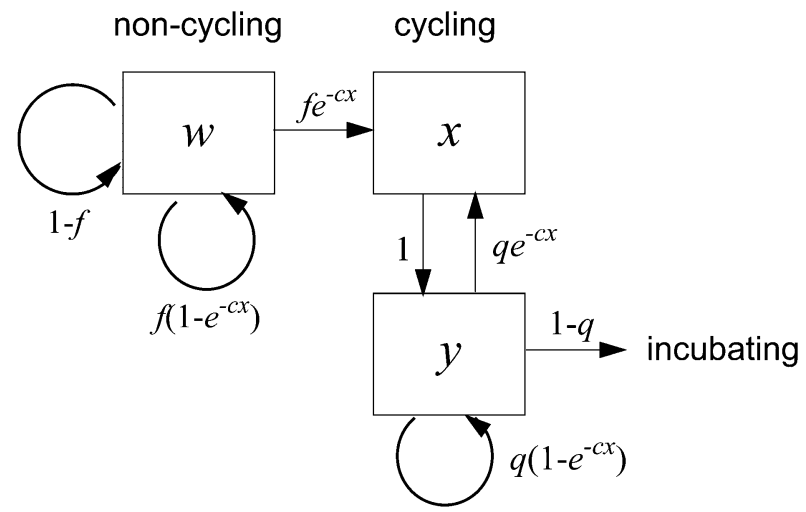

FIG. 4. Conceptual diagram for Model 6.

begin to incubate. The number $w_{t+1}$ of noncycling individuals at the next time step is the number that are not ready to cycle $\left(1-f_{t}\right) w_{t}$ plus the number that are ready to cycle but delay so as to synchronize $f_{t}\left(1-e^{-c_{t} x_{t}}\right) w_{t}$. The number $x_{t+1}$ of individuals in the first cycle phase at the next time step is the number $f_{t} w_{t} e^{-c x_{t}}$, which are ready to start cycling and do not delay, plus the number $q y_{t} e^{-c_{t} x_{t}}$ that return to the first phase from the second phase without delay. We assume that an individual in the first phase always enters the second phase at the next time step; hence, the number $y_{t+1}$ of individuals in the second phase at the next time step is the number $x_{t}$ leaving the first phase plus the number $q\left(1-e^{-c_{t} x_{t}}\right) y_{t}$ in the second phase that delay returning to the first phase.

By the third model assumption $M_{3}$, oviposition of an egg occurs 2 days after its ovulation. Thus, the number $E_{t+1}$ of eggs laid on day $t+1$ is the total number $x_{t-1}$ of ovulations on day $t-1$, and the number $I_{t+1}$ of clutches initiated on day $t+1$ is the number of first-time recruits to the ovulating class $x_{t-1}$ on day $t-1$ :

$$
\begin{aligned}
& E_{t+1}=x_{t-1} \\
& I_{t+1}=f_{t-2} w_{t-2} e^{-c_{t-2} x_{t-2}}
\end{aligned}
$$

We accounted for demographic stochasticity by adding noise on the square-root scale (Desharnais et al. 2006) and accounted for "lattice effects" (dynamic outcomes due to the discrete nature of animal numbers) by rounding the right-hand sides of the model equations at each iteration (Henson et al. 2001). The stochastic model equations, algebraically simplified, are

$$
\begin{aligned}
& w_{t+1}=\operatorname{round}\left[\left(\sqrt{\left(1-f_{t} e^{-c_{t} x_{t}}\right) w_{t}}+\sigma_{w} \varepsilon_{t 1}\right)^{2}\right] \\
& x_{t+1}=\operatorname{round}\left[\left(\sqrt{\left(f_{t} w_{t}+q y_{t}\right) e^{-c_{t} x_{t}}}+\sigma_{x} \varepsilon_{t 2}\right)^{2}\right] \\
& y_{t+1}=\operatorname{round}\left[\left(\sqrt{x_{t}+q y_{t}\left(1-e^{-c_{t} x_{t}}\right)}+\sigma_{y} \varepsilon_{t 3}\right)^{2}\right] \\
& I_{t+1}=\operatorname{round}\left[\left(\sqrt{f_{t-2} w_{t-2} e^{-c_{t-2} x_{t-2}}}+\sigma_{I} \varepsilon_{t 4}\right)^{2}\right] \\
& E_{t+1}=\operatorname{round}\left[\left(\sqrt{x_{t-1}}+\sigma_{E} \varepsilon_{t 5}\right)^{2}\right]
\end{aligned}
$$

where the sigmas are nonnegative constants and the epsilons are standard normal random variables (mean $=0, \mathrm{SD}=1$ ) uncorrelated in time. The quantities inside the squares are taken to be zero if negative.

Our clutch-initiation and oviposition time-series data corresponded to state variables $I$ and $E$, respectively. We expected little variation between the number $x_{t-1}$ of ovulations and the number $E_{t+1}$ of eggs laid 2 days later; hence, we assumed that $\sigma_{E}=0$ in Model 8. Consequently, oviposition data served as data for $x$ when appropriately lagged. Lacking data for state variables $w$ and $y$, however, we were unable to conduct rigorous maximum-likelihood parameter estimation (as in Dennis et al. 2001). Instead, we estimated the four parameters $\tilde{c}, r, b, q$ using data from area $\mathrm{C} 2006$ by setting the observed values of parameters $a=0, \mathrm{NN}=2.07, w_{0}=68, x_{0}=0$, and $y_{0}=0$ (Table 1) and minimizing the sums of squared departures (on the square-root scale; Dennis et al. 2001) of predicted $I$ and $E$ values from observed clutch-initiation and oviposition values. The predictions at each time step were conditioned (as far as possible) on the observed values at the previous step. This resulted in the parameters given in the caption of Figure 5. The generalized $R^{2}$ fits (Dennis et al. 2001) to area C 2006 data were $R_{1}^{2}=0.89$ and $R_{\mathrm{E}}^{2}=0.94$. We used Model 8, parameterized for area C 2006 , to make predictions for the other data sets without reparameterizing. Area C 2006 was chosen as the model-fitting data set because it had the lowest $P$ value in the test of the null model and, hence, showed the strongest evidence of process synchrony (see below; Table 1).

\section{Model Predictions}

Null model.-The predictions of the null models consist of distributions of $z$ values generated by those models (Fig. 5A); and the distributions, in turn, depend on model parameters (for example, $N, m, \bar{d}$, and $s$ in model $\mathrm{H}_{\mathrm{N}}$ ). Although the observed values of $m, \bar{d}$, and $s$ were similar among the data sets, the number of clutches $N$ varied considerably. Given fixed values of $m, \bar{d}$, and $s$, the critical $z$ value $z_{\text {crit }}$ is a decreasing function of $N$ (Fig. $6 \mathrm{~A}$, solid curve). Because the observed values of $m, \bar{d}$, and $s$ varied a small amount among sample areas, the actual critical values $z_{\text {crit }}$ for the 15 data sets do not lie exactly on the solid curve in Figure 6A and are shown as solid squares. The expected $z$ value (based on the null model) is also a decreasing function of $N$ (Fig. 6A, dashed curve). This is because random occurrences of synchrony are likely if the number of clutches $N$ is small, but rare if $N$ is large. The null model thus makes the following prediction.

(N1) If the null model describes the observed system, then the expected $z$ value is a decreasing function of the number of nests $\mathrm{N}$ (Fig. 6A, C).

The null models do not depend explicitly on colony density. However, among our study areas, $N$ happened to be a decreasing function of mean NN distance ( $P_{\text {trend }}=0.017 ; n=15$; Fig. 6B). This fact, coupled with prediction N1, implies the following prediction.

(N2) If the null model describes the observed system in this particular study, then the expected $z$ value is an increasing function of NN (Fig. 6D).

Process model.-The process model (Model 8) makes three general predictions, the first two of which are in direct opposition to predictions N1 and N2 of the null model.

(P1) If the process model describes the observed system, then the expected $z$ value is an increasing function of the number of 


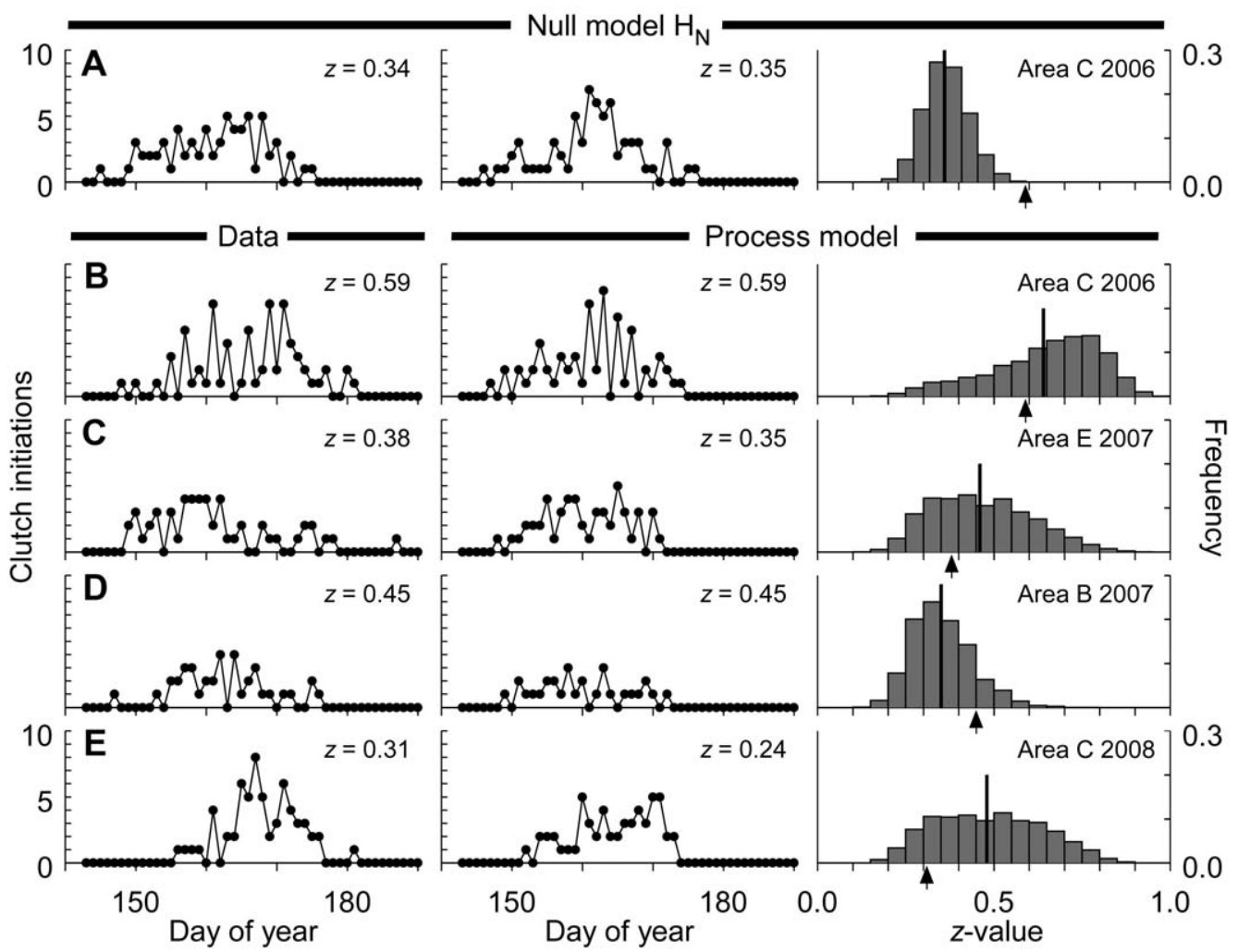

FIG. 5. Clutch-initiation data for Glaucous-winged Gulls at Violet Point, Protection Island National Wildlife Refuge, Washington (2006-2008), simulations, and distributions of $z$ values generated from simulations. Vertical bar indicates distribution mean; arrow indicates observed $z$ value (Table 1). (A) Two Monte Carlo simulations and distribution of $z$ values for 200,000 Monte Carlo simulations of null hypothesis $\left(\mathrm{H}_{\mathrm{N}}\right)$ for area $\mathrm{C} 2006$. Mean $=$ 0.36. Null hypothesis rejected $(P=0.0006)$. (B-E) Simulations are from Model 8. Parameters estimated for area C 2006 are $w_{0}=68, x_{0}=0, y_{0}=0$, $a=0, N N=2.07, \tilde{c}=0.78, r=29, b=0.0011$, and $q=0.62$. The estimation procedure resulted in crude estimates of variances $<1$. We used $\sigma_{w}=0.1, \sigma_{x}=0.3$, $\sigma_{y}=0.1, \sigma_{l}=0.3$, and $\sigma_{E}=0.0$. Distributions are for 10,000 simulations. (B) Area C $2006\left(w_{0}=68, N N=2.07\right)$. Mean $=0.64$. (C) Area E 2007; parameters adjusted for this area $\left(w_{0}=53, \mathrm{NN}=2.51\right)$. Mean $=0.46$. (D) Area B 2007; parameters adjusted for this area $\left(w_{0}=38, N N=3.44\right)$. Mean $=0.35$. (E) Area C 2008; parameters adjusted for this area $(\mathrm{NN}=1.94, \mathrm{a}=4.4)$. Mean $=0.48$.

TABLE 1. Test of null hypotheses $\mathrm{H}_{\mathrm{N}}$ and $\mathrm{H}_{\mathrm{A}}$

\begin{tabular}{|c|c|c|c|c|c|c|}
\hline Year & Variable & $\begin{array}{c}\text { Area A } \\
\left(877 \mathrm{~m}^{2}\right)\end{array}$ & $\begin{array}{c}\text { Area B } \\
\left(1,394 \mathrm{~m}^{2}\right)\end{array}$ & $\begin{array}{c}\text { Area C } \\
\left(836 \mathrm{~m}^{2}\right)\end{array}$ & $\begin{array}{c}\text { Area D } \\
\left(705 \mathrm{~m}^{2}\right)\end{array}$ & $\begin{array}{c}\text { Area E } \\
\left(393 \mathrm{~m}^{2}\right)\end{array}$ \\
\hline \multirow[t]{5}{*}{2006} & Number of clutches & 42 & 31 & 68 & 34 & 53 \\
\hline & Number of eggs & 104 & 74 & 164 & 81 & 119 \\
\hline & NN distance $\mathrm{a}^{\mathrm{a}}$ & 2.26 & 3.13 & 2.07 & 2.35 & 2.19 \\
\hline & $\mathrm{H}_{\mathrm{N}} \mathrm{z}(P)$ & $0.50(0.22)$ & $0.52(0.62)$ & $0.59\left(0.0006^{b}\right)$ & $0.44(0.65)$ & $0.60\left(0.004^{b}\right)$ \\
\hline & $\mathrm{H}_{\mathrm{A}} z(P)$ & $0.33(0.29)$ & $0.35(0.68)$ & $0.30(0.096)$ & $0.43(0.04)$ & $0.37(0.04)$ \\
\hline \multirow[t]{5}{*}{2007} & Number of clutches & 29 & 38 & 68 & 41 & 53 \\
\hline & Number of eggs & 65 & 89 & 166 & 97 & 124 \\
\hline & NN distance & 2.94 & 3.44 & 2.03 & 2.57 & 2.51 \\
\hline & $\mathrm{H}_{\mathrm{N}} \mathrm{z}(P)$ & $0.48(0.68)$ & $0.45(0.53)$ & $0.57\left(0.001^{b}\right)$ & $0.54(0.23)$ & $0.38(0.75)$ \\
\hline & $\mathrm{H}_{\mathrm{A}} \mathrm{z}(P)$ & $0.35(0.64)$ & $0.35(0.30)$ & $0.37\left(0.005^{b}\right)$ & $0.30(0.73)$ & $0.27(0.66)$ \\
\hline \multirow[t]{5}{*}{2008} & Number of clutches & 39 & 46 & 62 & 41 & 45 \\
\hline & Number of eggs & 95 & 110 & 158 & 108 & 101 \\
\hline & NN distance & 2.79 & 3.54 & 1.94 & 2.16 & 2.55 \\
\hline & $\mathrm{H}_{\mathrm{N}} \mathrm{Z}(P)$ & $0.49(0.37)$ & $0.37(0.72)$ & $0.31(0.68)$ & $0.46(0.36)$ & $0.38(0.69)$ \\
\hline & $\mathrm{H}_{\mathrm{A}}^{\mathrm{N}} z(P)$ & $0.34(0.35)$ & $0.21(0.94)$ & $0.25(0.32)$ & $0.42(0.015)$ & $0.28(0.61)$ \\
\hline
\end{tabular}

a Mean nearest-neighbor (NN) distances are in meters.

${ }^{b}$ Significant at the $\alpha=0.01$ level; $P$ values reported to the accuracy obtained by five sets of $10^{6}$ Monte Carlo simulations. 

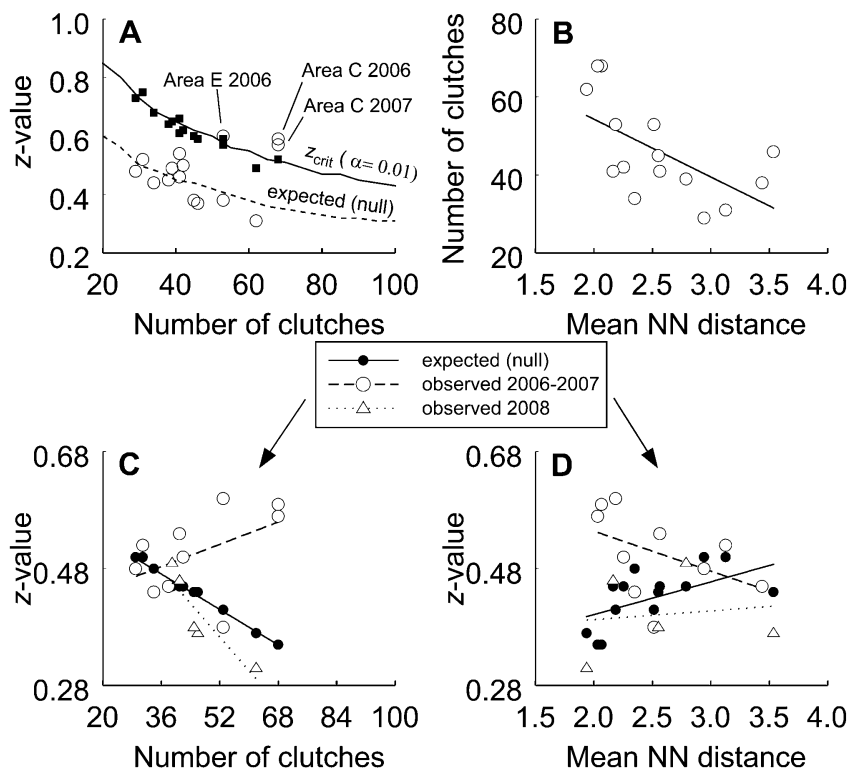

FiG. 6. Data $z$ values, numbers of Glaucous-winged Gull clutches, and mean NN distances. (A) Critical $z$ values for the $\alpha=0.01$ significance level $\left(\mathrm{H}_{\mathrm{N}^{\prime}}\right.$ solid squares) and actual $\mathrm{z}$ values (open circles) for all 15 data sets. For Monte Carlo parameters based on area C 2006-2007 $\left(\mathrm{H}_{\mathrm{N}^{\prime}} m=34\right.$, $\bar{d}=17, s=7.5), z_{\text {crit }}$ (solid line) and mean Monte Carlo $z$ value (dashed line) are shown as a function of number of clutches $N$. (B) Number of clutches and mean NN distance $\left(P_{\text {trend }}=0.017 ; n=15\right)$. (C) Mean Monte Carlo $z$ values $\left(\mathrm{H}_{\mathrm{N}^{\prime}}\right.$, solid circles $)$ decrease with $N\left(P_{\text {trend }}=0.00 ; n=15\right)$. Observed clutch-initiation $z$ values (open circles) showed the opposite trend in 2006-2007 (dashed line, $P_{\text {trend }}=0.16 ; n=10$ ). In 2008, observed values decreased with $N(P=0.041 ; n=5)$. There was no trend in 2006 2008 (open circles and open triangles, $P_{\text {trend }}=0.69 ; n=15$ ). (D) Mean Monte Carlo $z$ values $\left(\mathrm{H}_{\mathrm{N}^{\prime}}\right.$ solid circles) increase with mean $\mathrm{NN}$ distance ( $\left.n=15, P_{\text {trend }}=0.019\right)$. Observed clutch-initiation $z$ values (open circles) showed the opposite trend in 2006-2007 (dashed line, $P_{\text {trend }}=0.18 ; n=10$ ) and essentially no trend in 2008 (open triangles, $P_{\text {trend }}=0.84 ; n=5$ ).

nests $w_{0}$, given that the colony density $(\mathrm{NN})$ is held constant. This prediction occurs because deterministic signals are clarified at larger population sizes under the assumption of demographic stochasticity (Desharnais et al. 2006). In this case, the deterministic model signal is synchronous, so the expected model-synchrony level rises with the number of nests.

(P2) If the process model describes the observed system, then the expected $z$ value is a decreasing function of $\mathrm{NN}$, given that the number of nests $\left(w_{0}\right)$ is held constant. This prediction occurs because social stimulation (Model 5) is assumed to be inversely proportional to mean NN distance in the mathematical model.

(P3) If the process model describes the observed system, then a cool weather delay in the onset of laying decreases the expected $z$ value. This prediction occurs because, in the process model, the "final cue" (temperature) for reproduction has moved to a later date while the endpoints of the reproductive window have remained fixed. Intuitively, one might expect that a delay in the onset of laying would increase synchrony on a yearly timescale-that is, tighten the reproductive pulse-because birds that would have ovulated early are delayed to coincide with late starters. However, on a daily timescale, the model predicts a decreased level of ovulation synchrony. This is because the smaller time window does not allow sufficient time for the group of two-periodic oscillators to synchronize. (This is an example of a situation in which mathematical models can illustrate unexpected dynamic consequences.)

\section{Results}

Null models $H_{N}$ and $H_{U}$-Figure 6A compares the observed $z$ values (open circles) with the critical values $z_{\text {crit }}$ (solid circles) for null model $\mathrm{H}_{\mathrm{N}}$, and Table 1 lists observed $z$ values and $P$ values for null model $\mathrm{H}_{\mathrm{N}^{*}}$ (Results for $\mathrm{H}_{\mathrm{U}}$, not shown in Table 1, were equivalent in terms of significance to those of $\mathrm{H}_{\mathrm{N}}$.) During 2006-2007, the null models $\mathrm{H}_{\mathrm{N}}$ and $\mathrm{H}_{\mathrm{U}}$ were rejected at the $\alpha=0.01$ significance level $\left(P<0.005\right.$ for $\left.\mathrm{H}_{\mathrm{N}}\right)$ whenever mean NN distance was $<2.20 \mathrm{~m}$ (areas C and E in 2006 and area C in 2007; Fig. 2B-D), and neither hypothesis was rejected whenever mean NN distance was $\geq 2.20 \mathrm{~m}$. In 2008, neither $\mathrm{H}_{\mathrm{N}}$ nor $\mathrm{H}_{\mathrm{U}}$ could be rejected for any area.

Thus, during 2006-2007, clutch initiation showed strong evidence of process synchrony but only in dense areas of the colony. The area with the most nests, area $C$, showed the strongest evidence of process synchrony in clutch initiation $(P=0.0006$ in 2006 and $P=0.001$ in 2007 for $\left.H_{N}\right)$. In La Niña 2008, when the onset of laying was delayed, no area, including area $\mathrm{C}$, showed process synchrony in clutch initiation.

Null model $H_{A}$.- Results for null model $\mathrm{H}_{\mathrm{A}}$ were similar to those for null models $\mathrm{H}_{\mathrm{N}}$ and $\mathrm{H}_{\mathrm{U}}$, although the evidence was not as strong or consistent (Table 1).

Process model.-Predictions of the process model are consistent with the data. Panels A and B in Figure 5 compare the predictions of the null model $\mathrm{H}_{\mathrm{N}}$ and the process model (Model 8) to data from area C 2006; the arrows indicate the observed $z$ value, and the black vertical bars indicate the means of the distributions of $z$ values generated by the null model (Fig. 5A) and simulations of the stochastic process model (Fig. 5B).

Note the overlap of the distributions arising from the null model and the process model (Fig. 5A, B). This overlap suggests that a Type I error (rejecting the null model when it is true) is unlikely by the very nature of the Monte Carlo analysis, whereas a Type II error (failing to reject the null model when it is false) is quite likely because of demographic noise in the system. That is, a value of $z$ observed in a process-synchronous system could lie in the left-hand tail of the histogram in Figure 5B as well as the middle of the null histogram in Figure $5 \mathrm{~A}$-in which case the null model would not be rejected.

Panels $\mathrm{C}-\mathrm{E}$ in Figure 5 show data and predictions of the mathematical model for three other data sets in comparison to area C 2006 (Fig. 5B). For area E 2007, which had fewer clutches and larger mean NN distance $\left(w_{0}=N=53\right.$ clutches; $\mathrm{NN}=2.51$; Fig. 5C) than area C $2006\left(w_{0}=N=68\right.$; $N N=2.07$; Fig. 5B), the expected model $z$ value decreased notably (from 0.64 to 0.46 ). For area B 2007, which had even fewer clutches and larger mean NN distance $\left(w_{0}=N=38 ; \mathrm{NN}=3.44\right.$; Fig. $\left.5 \mathrm{D}\right)$, the expected model $z$ value decreased even more (to 0.35). For area C 2008 (delay $a=$ 4.4 days; Fig. 5E), the model predicts a decreased expected $z$ value (0.48) as compared with area C 2006 (delay $a=0$ days; Fig. 5B). These specific outcomes are consistent with the three general predictions (P1-P3) of the process model (Model 8). 
Test of predictions N1 and P1.-The 2006-2007 data were consistent with prediction P1, and the 2008 data were consistent with prediction N1. Linear regression of observed clutch-initiation $z$ values on $N$ showed a positive trend in 2006-2007 $\left(P_{\text {trend }}=0.16\right.$; $n=10$; Fig. $6 \mathrm{C})$ and a negative trend in $2008\left(P_{\text {trend }}=0.04 ; n=5\right.$; Fig. 6C). There was essentially no trend in 2006 $-2008\left(P_{\text {trend }}=0.69\right.$; $n=15)$.

Test of predictions N2 and P2.-The 2006-2007 data were consistent with prediction P2. Linear regression of observed clutch-initiation $z$ values on mean $\mathrm{NN}$ distance showed a negative trend in 2006-2007 ( $P_{\text {trend }}=0.18 ; n=10$; Fig. 6D) and essentially no trend in $2008\left(P_{\text {trend }}=0.84 ; n=5\right.$; Fig. 6D).

\section{Discussion}

In 2006-2007, data from dense areas of the colony showed evidence of every-other-day process synchrony in oviposition, and strong evidence of every-other-day process synchrony in clutch initiation, through significant departure from null Monte Carlo predictions (Table 1 and Fig. 5A). Furthermore, contrary to the expectations generated by the null models, observed synchrony levels rose with increasing numbers of nests and declined with increasing mean NN distance (Fig. 6C, D), which suggests that synchrony was socially stimulated. Data sets for all years comported with the predictions of a mathematical model based on hypothetical mechanisms of ovulatory synchronization and cool-weather delay.

General tenets.-Several general tenets arise from the modeling approach. (1) For a club with few nests, it is unlikely that one can distinguish process synchrony from randomness. (2) In a club with process synchrony, an increase in club density increases the expected level of synchrony if the number of nests is held constant. (3) In a club with process synchrony, an increase in the number of nests increases the expected level of synchrony if the club density is held constant. (4) In a club with process synchrony, a delay in the onset of laying may decrease the expected level of synchrony (see the sixth entry under "Caveats" below). (5) The observer of a system with a synchronizing mechanism should not expect to identify process synchrony in every time series (because a Type II error is likely), whereas the observer of a system without a synchronizing mechanism is unlikely to identify process synchrony in any time series (because a Type I error is unlikely).

Looking for synchrony.-Our study illustrates that synchrony may be difficult to detect. How should researchers searching for synchrony in other colonies and species choose study sites and collect data in a way that will optimize the possibility of success? First, the time interval between nest checks should be suitable for the characteristic egg-laying interval of the species in question. For example, if the egg-laying interval is $\geq 2$ days, then nest checks can be conducted daily at the same time of day. If the egg-laying interval is 1 day, then more frequent observations are required. Second, data should be collected from a socially coherent unit (i.e., our "clubs") rather than from an arbitrary geographic area. Because the positions of clubs move from year to year, one may have to use different geographic boundaries every year. Third, an observed club must contain a sufficient number of nests. Table 1 suggests that a general rule of thumb for Glaucous-winged Gulls may be $\geq 50$ clutches. In particular, pairwise analysis in which nearest-neighbor pairs are compared with pairs randomly chosen from the colony cannot be expected to show significance. Fourth, the club must be sufficiently dense; that is, the nests should be sufficiently close together. Table 1 suggests a mean NN distance of $\leq 2.2 \mathrm{~m}$ as a rule of thumb for Glaucous-winged Gulls. Fifth, weather conditions should be average for the region, and the club should experience minimal disturbance, because stress can affect hormone levels. Sixth, it is important to remember that, even if the system contains the mechanisms of process synchrony, one cannot expect to always observe significant process synchrony in time-series data.

In 2009, we conducted a test of the guidelines presented above. From the vantage of a 30-m bluff overlooking the Violet Point Glaucous-winged Gull colony, we looked for a large, dense club that experienced minimal disturbance. The area of the colony that best satisfied these criteria consisted of a club lying to the west of area $\mathrm{C}$ and including about one half of the area of the west end of area $C$ (Fig. 1, dotted lines). This club contained 69 clutches and a mean $( \pm$ SD) NN distance of $1.80 \pm 0.73 \mathrm{~m}$. The 2009 clutchinitiation data from this club showed some evidence of synchrony $\left(P=0.077\right.$ for $\mathrm{H}_{\mathrm{N}} ;$ Fig. 2E), although not significance at the $\alpha=0.01$ level. The inclusion of the rest of area $C$ in this club yielded $P=$ 0.045 , with 109 clutches and mean NN distance of $1.86 \pm 0.72 \mathrm{~m}$.

Caveats.-A number of caveats should be stated. First, the sample areas used in 2006-2008 were chosen as part of a reproductive study of the colony; they were not designed to study reproductive synchrony. There are several reasons why the areas were not ideal for such a study. For example, two of the five areas (areas C and D; Fig. 1) were not completely socially isolated, and some of the same birds nested in the same areas from year to year; hence, the 15 data sets were not independent across sample areas or years. However, we believe that the modeling approach used here points the way to designing experiments to test for synchrony.

Second, we have considered only one species, in one colony. We encourage other researchers to look for synchrony in other colonies and species. It is not clear at this point whether the synchrony we observed is a robust phenomenon.

Third, we have focused here on the existence of egg-laying synchrony and its connection to colony density; the mechanisms that might lead to egg-laying synchrony remain unknown. The hypothesis that egg-laying synchrony indicates ovulation synchrony is difficult, but not impossible, to test non-invasively in wild birds. In ongoing studies, we are testing this hypothesis by monitoring metabolites of hormones in feces. In general, the hypotheses that underlie assumptions $M_{1}-M_{3}$ (on which the mathematical model is based) involve complicated systems of endocrine activity. Although assumptions $M_{1}$ and $M_{2}$ are motivated by empirical evidence of the effect of temperature on baseline LH levels in White-crowned Sparrows (Zonotrichia leucophrys; Wingfield et al. 1996, 1997, 2003; Maney et al. 1999) and the effect of temperature on the onset of laying in gulls (Verbeek 1979, Schreiber 2001), these assumptions may not hold in our particular case. Silverin and Viebke (1994), for example, showed experimentally that low temperatures affect gonadotropin cycles differently in closely related species of European tits (Parus spp.).

Fourth, the process model (Model 8) is a vastly simplified expression of a possible mechanism for synchrony. It does not accommodate the range of complicated biological possibilities. For example, it does not include the possibility that females in the first day of the ovulation cycle may experience acceleration or delay 
of LH surges; it only allows females in the second day of the cycle to delay. As a discrete-time model, it does not address endocrine changes occurring continuously through time that could lead to acceleration or delay. Nevertheless, the model provides a simple way to explore dynamic consequences of hypotheses until the actual physiological mechanisms are understood.

Fifth, clutch initiations showed stronger evidence of process synchrony than total ovipositions. This may be because the mechanism of synchronization acted primarily on the initial LH surge; but more likely it is because our Monte Carlo simulations of model $\mathrm{H}_{\mathrm{A}}$ were more constrained than those of models $\mathrm{H}_{\mathrm{N}}$ and $\mathrm{H}_{\mathrm{U}}$. We used not only the observed values of $N, m, \bar{d}$, and $s$ as Monte Carlo parameters in $\mathrm{H}_{\mathrm{A}}$, but also the mean and variance of the observed laying intervals, forcing the simulations to closely resemble the observed time series.

Sixth, we note that there are two separate issues involved in discussing the observations and predictions for La Niña 2008: (1) cool-weather delay in the onset of laying and (2) the (possibly associated) decrease in synchrony. As for the first issue, cool weather is known to delay the onset of laying in Glaucous-winged Gulls and similar species (Verbeek 1979, Schreiber 2001). Although this is consistent with the delay that we observed in La Niña 2008, the observed delay could have been attributable, at least in part, to some other cause. As for the second issue, it is the mathematical model (Model 6) that predicts a decrease in synchrony resulting from cool-weather delay of laying. Although this prediction is consistent with the lack of synchrony observed in 2008 , it is premature to claim a causal link.

Seventh, although every-other-day egg-laying synchrony is a novel result that seems to defy the possibility of circadian entrainment, it is nevertheless possible that the synchrony was environmentally forced. This is unlikely, however, because 7 of the 10 data sets for 2006-2007 did not show synchrony.

Possible synchronizing mechanisms.-Groups of oscillators that synchronize spontaneously do so by means of some type of "communication." Synchronizing mechanisms for LH oscillators could be visual, auditory, and/or olfactory communication and could involve the presence and behavior of males. Avian hormone cycles are known to respond to a variety of visual and auditory communicative signals. For example, ovarian follicles grow faster in female Willow Tits (Parus montanus) in the presence of males than in the presence of other females (Silverin and Westin 1995), and LH release in female Ring Doves (Streptopelia risoria) is stimulated by male displays and cooing by both males and females (Cheng et al. 1998). Accumulating evidence suggests that birds, including gulls, also communicate using odoriferous chemicals generated by the uropygial gland and elsewhere in the body (Bang and Cobb 1968, Shibuya et al. 1970, Matsuzaki 1995, Roper 1999, Hagelin and Jones 2007, Wenzel 2007).

Selective advantage.-The question of possible selective advantage is the most difficult to address. In the case of seasonal (Fraser Darling effect) synchrony in colonial birds, it has been suggested that predator satiation may confer a selective advantage (Darling 1938). In the case of estrous synchrony in Norway Rats (Rattus norvegicus), it has been suggested that reproductive success may be enhanced in the context of synchronous group mating (McClintock 1984b). It is unclear how either of these hypotheses would apply to every-other-day synchrony in monogamous birds, such as gulls, that store sperm (Shugart 1988). It is possible that reproductive synchrony is an epiphenomenon without selective advantage (McClintock 1981, 1998). In future studies, we will explore possible selective advantages using mathematical models and the techniques of evolutionary game theory (Vincent and Brown 2005).

Conclusion.-We have shown that if social groups of colonial birds are sufficiently dense, higher-frequency synchronized reproductive oscillations can form within the annual reproductive pulse. Documentation of reproductive synchrony across a range of taxa hints at underlying physiological and adaptive processes that are poorly understood but deserving of further attention.

\section{ACKNOWLEDGMENTS}

We thank K. Ryan, project leader, Washington Maritime National Wildlife Refuge Complex, U.S. Fish and Wildlife Service, for permission to work on Protection Island National Wildlife Refuge and Rosario Beach Marine Laboratory for logistical support. We also thank an anonymous reviewer for valuable suggestions. Financial support was provided by Andrews University faculty grants to J.L.H. and S.M.H and by National Science Foundation grants DMS-0613899 (to S.M.H, J.L.H., and J.M.C.) and DMS0614473 (to J.G.G.)

\section{Literature Cited}

BANG, B. G., AND S. Совв. 1968. The size of the olfactory bulb in 108 species of birds. Auk 85:55-61.

Cheng, M.-F., J. P. Peng, And P. Johnson. 1998. Hypothalamic neurons preferentially respond to female nest coo stimulation: Demonstration of direct acoustic stimulation of luteinizing hormone release. Journal of Neuroscience 18:5477-5489.

Darling, F. 1938. Bird Flocks and the Breeding Cycle. Cambridge University Press, Cambridge, United Kingdom.

Dawson, A., AND P. J. Sharp. 2007. Photorefractoriness in birdsPhotoperiodic and non-photoperiodic control. General and Comparative Endocrinology 153:378-384.

Dennis, B., R. A. Desharnais, J. M. Cushing, S. M. Henson, And R. F. Costantino. 2001. Estimating chaos and complex dynamics in an insect population. Ecological Monographs 71:277-303.

Desharnais, R. A., R. F. Costantino, J. M. Cushing, S. M. HenSON, B. DENNIS, AND A. A. KING. 2006. Experimental support of the scaling rule for demographic stochasticity. Ecology Letters 9:537-547.

FAABORG, J. 1988. Ornithology: An Ecological Approach. Prentice Hall, Englewood Cliffs, New Jersey.

HAgELIN, J. C., AND I. L. Jones. 2007. Bird odors and other chemical substances: A defense mechanism or overlooked mode of intraspecific communication? Auk 124:741-761.

Hahn, T. P., T. Boswell, J. C. Wingfield, and G. F. Ball. 1997. Temporal flexibility in avian reproduction: Patterns and mechanisms. Pages 39-80 in Current Ornithology, vol. 14 (V. Nolan, Jr., E. D. Ketterson, and C. F. Thompson, Eds.). Plenum Press, New York.

Hahn, T. P., and S. A. MacDougall-Shackleton. 2008. Adaptive specialization, conditional plasticity and phylogenetic history in the reproductive cue response systems of birds. Philosophical Transactions of the Royal Society of London, Series B 363:267-286. 
Hahn, T. P., H. E. Watts, J. M. Cornelius, K. R. Brazeal, And S. A. MacDougall-Shackleton. 2009. Evolution of environmental cue response mechanisms: Adaptive variation in photorefractoriness. General and Comparative Endocrinology 163:193-200

Henson, S. M., R. F. Costantino, J. M. Cushing, R. A. DesharNAIS, B. Dennis, AND A. A. KIng. 2001. Lattice effects observed in chaotic dynamics of experimental populations. Science 294 602-605.

LiU, H.-K., K. E. Nestor, D. W. Long, AND W. L. BACON. 2001. Frequency of luteinizing hormone surges and egg production rate in turkey hens. Biology of Reproduction 64:1769-1775.

Maney, D. L., T. P. Hahn, S. J. Schoech, P. J. Sharp, M. L. MorTON, AND J. C. WingFiELD. 1999. Effects of ambient temperature on photo-induced prolactin secretion in three subspecies of White-crowned Sparrow, Zonotrichia leucophrys. General and Comparative Endocrinology 113:445-456.

Matsuzaki, O. 1995. Numbers of olfactory receptor cells and fine structure of olfactory nerves in various birds. Zoological Science 12:117-123.

MCClintock, M. K. 1971. Menstrual synchrony and suppression. Nature 229:244-245.

MCCLintock, M. K. 1981. Social control of the ovarian cycle and the function of estrous synchrony. American Zoologist 21:243-256.

MCClintock, M. K. 1984a. Estrous synchrony: Modulation of ovarian cycle length by female pheromones. Physiology \& Behavior 32:701-705.

MCClintock, M. K. 1984b. Group mating in the domestic rat as a context for sexual selection: Consequences for analysis of sexual behavior and neuroendocrine responses. Pages 1-50 in Advances in the Study of Behavior, vol. 14 (J. Rosenblatt, C. Beer, and R. Hinde, Eds.). Academic Press, New York

MCClintock, M. K. 1998. Whither menstrual synchrony? Annua Review of Sex Research 9:77-95.

Nicholls, T. J., A. R. Goldsmith, And A. Dawson. 1988 Photorefractoriness in birds and comparison with mammals. Physiological Reviews 68:133-176.

Patterson, I. J. 1965. Timing and spacing of broods in the Blackheaded Gull Larus ridibundus. Ibis 107:433-459.

Pikovsky, A., M. Rosenblum, AND J. Kurths. 2003. Synchronization: A Universal Concept in Nonlinear Sciences. Cambridge University Press, Cambridge, United Kingdom.

Roper, T. J. 1999. Olfaction in birds. Pages 247-322 in Advances in the Study of Behavior, vol. 28 (P. J. B. Slater, J. S. Rosenblatt, C. T. Snowdon, and T. J. Roper, Eds.). Academic Press, New York.

Schreiber, E. A. 2001. Climate and weather effects on seabirds Pages 179-216 in Biology of Marine Birds (E. A. Schreiber and J. Burger, Eds.). CRC Press, Boca Raton, Florida.

Shibuya, T., M. IIJIma, And K. TonOSAKI. 1970. Responses of the olfactory nerve in the seagull, Larus crassirotris. Zoological Magazine 79:237-239.

ShugART, G. W. 1988. Uterovaginal sperm-storage glands in sixteen species with comments on morphological differences. Auk 105:379-384.
Silverin, B., AND P. A. ViebKe. 1994. Low temperatures affect the photoperiodically induced LH and testicular cycles differently in closely related species of tits (Parus spp.). Hormones and Behavior 28:199-206.

Silverin, B., AND J. Westin. 1995. Influence of the opposite sex on photoperiodically induced LH and gonadal cycles in the Willow Tit (Parus montanus). Hormones and Behavior 29:207-215.

Strogatz, S. 2003. Sync: The Emerging Science of Spontaneous Order. Hyperion, New York.

Verbeek, N. A. M. 1979. Timing of primary molt and egg-laying in Glaucous-winged Gulls. Wilson Bulletin 91:420-425.

VermeER, K. 1963. The breeding ecology of the Glaucous-winged Gull (Larus glaucescens) on Mandarte Island, British Columbia. Occasional Papers of the British Columbia Provincial Museum, no. 13.

VinCEnt, T. L., AND J. S. BROwn. 2005. Evolutionary Game Theory, Natural Selection, and Darwinian Dynamics. Cambridge University Press, Cambridge, United Kingdom.

Wenzel, B. M. 2007. Avian olfaction: Then and now. Journal of Ornithology 148 Supplement 2:S191-S194.

WiebE, K. L., AND K. MARTIN. 1995. Ecological and physiological effects on egg laying intervals in ptarmigan. Condor 97:708-717.

WingFIELD, J. C. 2008. Organization of vertebrate annual cycles: Implications for control mechanisms. Philosophical Transactions of the Royal Society of London, Series B 363:425-441.

Wingfield, J. C., T. P. Hahn, D. L. Maney, S. J. Schoech, M. WAdA, AND M. L. Morton. 2003. Effects of temperature on photoperiodically induced reproductive development, circulating plasma luteinizing hormone and thyroid hormones, body mass, fat deposition and molt in Mountain White-crowned Sparrows, Zonotrichia leucophrys oriantha. General and Comparative Endocrinology 131:143-158.

Wingfield, J. C., T. P. Hahn, M. WadA, L. B. Astheimer, And S. SCHOECH. 1996. Interrelationship of day length and temperature on the control of gonadal development, body mass, and fat score in White-crowned Sparrows, Zonotrichia leucophrys gambelii. General and Comparative Endocrinology 101:242-255.

Wingfield, J. C., T. P. Hahn, M. Wada, and S. J. Schoech. 1997. Effects of day length and temperature on gonadal development, body mass, and fat depots in White-crowned Sparrows, Zonotrichia leucophrys pugetensis. General and Comparative Endocrinology 107:44-62.

Yang, J., J. L. M. Morgan, J. D. Kirby, D. W. Long, And W. L. BACON. 2000. Circadian rhythm of the preovulatory surge of luteinizing hormone and its relationships to rhythms of body temperature and locomotor activity in turkey hens. Biology of Reproduction 62:1452-1458.

Zador, S. G., AND J. F. Piatt. 2007. Simulating the effects of predation and egg-harvest at a gull colony. Pages 188-192 in Proceedings of the Fourth Glacier Bay Science Symposium, October 26-28, 2004 (J. F. Piatt and S. M. Gende, Eds.). U.S. Geological Survey Scientific Investigations Report 1007-5047.

Associate Editor: T. P. Hahn 